\title{
ENFOQUE CRIMINOLÓGICO DE LA VIOLENCIA DE GÉNERO E INTRAFAMILIAR ¿ES EFICAZ LA RESPUESTA PENAL?
}

\section{CRIMINOLOGICAL APPROACH OF GENDER AND INTRAFAMILY VIOLENCE IS THE CRIMINAL RESPONSE EFFECTIVE?}

\author{
Dr. Dr. Dr. H.C. Gino Ríos Patio \\ Director del Instituto de Investigación Jurídica \\ Universidad de San Martín de Porres \\ griosp@usmp.pe \\ www.ginoriospatio.com \\ Perú, Lima
}

\section{SUMARIO}

- Introducción

- Sobre la violencia

- La violencia de género

- La violencia intrafamiliar

- La reacción penal

- Conclusiones

\section{RESUMEN}

El autor expone desde una perspectiva criminológica las causas de la violencia de género e intrafamiliar y analiza si la respuesta penal es eficaz para prevenir y reducir este tipo de violencia. Propone lineamientos de política criminológica para hacer frente al incremento de estas conductas agresivas que erosionan el núcleo familiar y por consiguiente la base social.

\footnotetext{
ABSTRACT

The author exposes, from a criminological perspective, the causes of gender and intrafamily violence and analyzes whether the criminal response is effective in preventing and reducing this type of violence. It proposes criminological policy guidelines to face the increase of these aggressive behaviors that erode the family nucleus and therefore the social base.
}

\section{PALABRAS CLAVE}

Violencia intrafamiliar; violencia de género; política criminológica; criminalización de conductas domésticas.

\section{KEYWORDS}

Domestic violence; gender violence; criminological policy; criminalization of domestic behavior.

\section{INTRODUCCIÓN}

En el marco de una sociedad estructural, institucional, comportamental y discursivamente violenta, los índices de la violenciaintrafamiliarydegénerosehanelevado en nuestro país en los últimos años. Como respuesta a esta situación, la criminalización y penalización de las correspondientes conductas se ha incrementado. La resonancia mediática de este tipo de agresividad se acrecienta exagerando el tratamiento de la noticia con una sobre exposición y lenguaje sensacionalista. El resultado no se hace esperar: más violencia intrafamiliar y de género; más padres de familia encarcelados; y más niños perturbados por el drama que los aflige. Ante tan álgido problema social, es objetivo del presente artículo enfocar las verdaderas causas de estos tipos de violencia y contrastarlas con la respuesta penal que el Estado da infructuosamente, con 
el propósito de evaluar su ineficacia y postular lineamientos de política criminológica para coadyuvar a la prevención, reducción y control de la situación.

A tal efecto, se desarrolla la conceptualización que tienen las agencias penales acerca de la violencia como aspecto individual de una persona agresora; se explora el cariz socio político del concepto, involucrando en el estudio no solo a la víctima sino también a la comunidad y la autoridad; se examina la idoneidad de la respuesta estatal frente a la problemática; y se plantean lineamientos de política criminológica para hacer frente a una situación que de no encontrar solución en el corto plazo agravará el escenario nacional por la descomposición social integral que se puede derivar de ella.

La familia, fuerza es reiterarlo, constituye la célula básica de la sociedad. Es el primer espacio natural donde el ser se humaniza, principia a perfilarse como persona social, en permanente interacción con los demás seres. En ella se forma al hombre, enseñándose y aprendiendo todo aquello que distingue a una persona, como es el ejercicio sereno de la razón con prevalencia sobre la emoción, el accionar responsable de la libertad, la consideración básica de la igualdad y el respeto a la dignidad humana.

Lo que se enseña-aprende en el núcleo familiar a temprana edad, queda impreso indeleblemente en la psique del individuo y será pulsión incontrolable o hábito irrefrenable en la conducta personal y social, en la vida privada y pública. Y no estamos hablando del nivel socio económico cultural que puede tener una determinada familia, tan solo nos estamos refiriendo a la familia como institución social, pues la impronta de lo enseñado-aprendido en su interior permanece durante toda la vida humana en estado latente. El conocimiento, el dinero, el linaje o cualquier otro timbre de distinción artificial resulta secundario y estéril para detener o hacer aparecer, según el caso, lo que se enseñó-aprendió o no en el seno familiar. Una vez (mal) formado el hombre es sumamente difícil desviarlo o re encaminarlo.

Por eso, formar una familia implica una responsabilidad social de confianza, auxilio y amparo, que tiene su base en el amor que puede nacer entre dos personas, con la finalidad de forjar a hombres plenos de capacidad y compromiso.
Lo anterior, no obstante, hoy en día, en nuestro país, los miembros de una familia soportan padecimientos generados por la violencia física, verbal, gestual o conductual de gravedad variada, por parte de los propios miembros de su familia, igual o mayor que el daño que pueden sufrir de terceras personas ajenas a su núcleo.

Semejante escenario nos impele a reflexionar en el presente artículo acerca de si la familia es una institución social desnaturalizada, debilitada y disminuida en el siglo XXI, a causa de un individualismo narcisista exacerbado por la globalización y la tecnología, que la ha convertido en un espacio de hostilidad y discordia en vez de fraternidad y concordia; de competencia soterrada en lugar de cooperación abierta; en un campo no de batalla en donde combaten fuerzas iguales, sino en un campo de cruel concentración de poder unilateral; $\mathrm{y}$ en una zona de violencia desembozada $y$ no en un lugar de verdadero amor, que ha originado que el ius puniendi estatal ingrese al hogar a castigar, lamentablemente de manera tan violenta como la conducta que pretende sancionar, reproduciendo las condiciones de desigualdad y discriminación sociales y familiares; y lo que es peor agravando el conflicto subyacente que existe debajo de toda violencia y sedimentándolo en la sociedad, antes de solucionarlo de manera extra penal.

\section{SOBRE LA VIOLENCIA}

La palabra violencia procede del latín violentia, cualidad de violentus. A su vez, ésta deriva de vis que significa fuerza; y de olentus que quiere decir abundancia ${ }^{1}$. Se aprecia entonces que el que actúa con mucha fuerza actúa violentamente. Ahora bien, la palabra hombre emana del latín vir de donde desciende viril y virilidad; asimismo la palabra hombría desciende de virtus, que después se extendió como virtud o cualidad que deberían tener los varones.

Por otra parte, la palabra fuerza, según el Diccionario de la Real Academia Española de la Lengua, quiere decir poder para sacar o desplazar a algo o a alguien que ejerza resistencia u obligarlo a alguien a que haga

\footnotetext{
1 Diccionario Etimológico. Disponible en: http://etimologias. dechile.net/?violencia
} 
Criminological approach of gender and intrafamily violence is the criminal response effective?

algo $^{2}$, esto es, para conseguir lo que uno quiere por encima de la voluntad de otra persona.

El uso de la fuerza física excesiva a nivel individual se asoció históricamente con el varón, debido a la existencia de la hormona testosterona, producida por las glándulas testículos y responsable del apetito sexual en los varones, por lo que se cree que es la causa de la agresividad y violencia en ellos. Sin embargo, los procesos químicos del organismo humano revelan que la hormona adrenalina, producida en momentos de elevada tensión emocional, eleva la presión sanguínea y el ritmo cardíaco, detonando en violencia por la necesidad de expeler, proyectar hacia afuera dicha emoción; asimismo el elemento químico cerebral dopamina genera una sensación de placer cuando una persona vence. La adrenalina y la dopamina también están presentes en el organismo de la mujer.

Quiere decir entonces que el uso de la fuerza abundante, se relacionó siempre al varón, pero también está coligado a la mujer, sobretodo porque la idea de violencia no se circunscribe únicamente a la fuerza física, sino también a otras manifestaciones de la fuerza, para vencer una resistencia e imponer la voluntad, obteniendo lo que uno desea. Se trata, en definitiva, de una acción de poder. De ahí que existan algunas conductas omisivas que igualmente lo manifiesten, como el hecho de ignorar o dejar de hablar a una persona con la que se integra un grupo familiar, laboral, educativo o de cualquier tipo; y también expresiones sofisticadas de poder que expresan argucia, sagacidad y fingimiento permanentes para lograr imponerse sobre la voluntad del otro. Evidentemente, el poder está siempre asociado a un fin, que, en el caso de la fuerza abundante o violencia, en cualquiera de sus formas, es un propósito de dominación.

Así como la violencia entraña poder, es decir doblegar, vencer la voluntad del otro, también involucra conflictividad, esto es, la confrontación de intereses disímiles, no necesariamente incompatibles, sino que lo parecen, quizás porque no se sabe expresarlos o por una cuestión de actitud, los mismos que bien podrían unirse para coadyuvar al logro del fin que se persigue, de manera cooperativa, no competencial, para superar y dar solución al conflicto.

\footnotetext{
2 Tomado de DRAE. Disponible en: http://dle.rae.
es/?id=IYwPBb3
}

Estamos frente a la tríada conflicto-violenciapoder que esclaviza al ser humano, más en esta época en que se da un exacerbamiento del yo, debido al individualismo egocéntrico y narcisista al que nos conduce la globalización con el nuevo paradigma planetario que ha hecho colapsar la identidad nacional, con lo cual la trasmisión de hábitos, costumbres, ideas y comportamientos es cosmopolita, sin que importe la realidad nacional ni la situación personal en la que cada quien se encuentre; la alta tecnología, que así como presenta muchas ventajas también cuenta entre sus desventajas el automatizar al ser humano y volverlo cada vez menos reflexivo y crítico, más inmediatista y efectista; y el neo liberalismo, proyecto hegemónico económico que en aras de la libertad económica subordina a todas las demás libertades humanas. Frente a esto cabe preguntarse si el ser humano puede soportar el peso de la presión e influencia de tales factores que lo acosan y agobian, socavando a su paso todo aquello que se resista, inclusive la familia.

Hay una nueva cultura que ha irrumpido en el horizonte de la modernidad, la cual está colisionando con la cultura pre existente, de raigambre patriarcal. Varón y mujer están siendo arrastrados en esta vorágine de la nueva civilización. Es un estadio transicional que viene ocasionando mucha conflictividad y violencia. Frente a esto se debe responder con educación, valores, cultura y auto control. Precisamente lo que la civilización actual nos escatima. De forma tal que la persona humana debe transformarse, resistiendo con reflexión y deliberación a la automatización.

La violencia es una forma de comportamiento, la cual nace en el entorno del ser humano. Y claro, es el primer espacio de socialización de éste en el que aparece primero y más constantemente, en una multiplicidad de formas, tales como el maltrato emocional (enojos, insultos, etc.) la intimidación, el abuso físico y sexual, entre otras, principalmente hacia mujeres y niños, de ahí que debe ser enfocada a partir de distintas perspectivas, como la biológica, psicológica, psiquiátrica, contextual, específica y social.

En realidad, la violencia es inmarcesible y omnipresente, multidimensional y plurifactorial, lo cual no significa que no sea posible prevenirla y reducirla personal y socialmente. La violencia intrafamiliar y la de género son algunas de las expresiones de un fenómeno más complejo, pero no hay lugar o 
situación donde potencial o realmente no se exprese la violencia. Las tensiones generadas al interior de la familia o del centro laboral, educativo o social se expresan recíprocamente.

Los probables factores desencadenantes de la violencia son de raíz biológica, psicológica, social, económica y cultural. Garza, E. (1994) ha asociado algunos casos de violencia con lesiones en el sistema límbico, en los lóbulos frontales y temporales y con anormalidades en el funcionamiento de la serotonina. En este caso, por ejemplo, se trataría de un factor orgánico, el cual frente a un estímulo externo haría detonar un comportamiento agresivo y violento. Hay, sin embargo, otros factores, como los de índole psicológica, como una baja autoestima, una depresión, una intolerancia a la frustración, entre otros. También los factores sociales, culturales y económicos inciden en la formación de conflictos que se pretenden solucionar mediante conductas violentas, terminando por descomponerse más o agravarse. Como se puede apreciar, las causas de la violencia son complejas y su análisis debe evaluar los factores biológicos, el medio ambiente inmediato, los factores de tipo social y familiar y los aspectos culturales en que se encuentran inmersos los intervinientes.

\section{LA VIOLENCIA DE GÉNERO}

El origen de la violencia del varón contra la mujer se pierde en la noche de los tiempos. Alberdi, I. y Matas, N. (2002) nos recuerdan que desde la perspectiva de las teorías evolutivas las diferencias biológicas entre los hombres y las mujeres, que les hace desempeñar un papel diferente en la reproducción humana, estarían en el origen de sus diferentes funciones sociales; asimismo que inicialmente se produjo un reparto de trabajo según el cual las mujeres se dedicaron a parir y a criar a los hijos, en cambio los hombres se dedicaron a buscar el alimento y a proteger al grupo, siendo precisamente la necesidad de protección que tuvieron las mujeres en sus períodos de reproducción, que abarcaba su vida fértil en las sociedades primitivas, el origen de la dependencia femenina; luego vendría la especialización de cada género, lo que explicaría un mayor desarrollo de las capacidades domésticas en las mujeres y las sociales y guerreras en los hombres, al tiempo que la evolución potenció la fuerza física de los hombres como característica vinculada a las funciones de protección y lucha en el exterior, produciéndose a favor de éstos una ventaja comparativa en cuanto al intercambio social y a sus capacidades de dominio exterior. Son esta fuerza y capacidad que utilizaron paulatinamente para desarrollar el poder masculino y someter a las mujeres.

Según Lerner, G. (1990) la teoría de LéviStrauss acerca de las estructuras elementales del parentesco, explica que el intercambio de mujeres es la forma inicial de establecer alianzas entre los grupos sociales más simples. En efecto, los matrimonios que los hombres pactan entre sí entregándose respectivamente a sus hermanas, serían las formas primitivas de pacto político. Basándose en ello, Lerner afirma que una de las primeras modalidades del comercio es el intercambio de mujeres, para lo cual hay que dominarlas antes, lo cual sería la explicación de la aparición original de la violencia, ya que no puede haber dominio y disposición sobre las mujeres sin alguna forma de violencia, ya sea usando la fuerza sobre ellas o simplemente la amenaza para lograr su obediencia.

Siguiendo a Lerner, la diferenciación de tareas entre hombres y mujeres viene a ser la primera forma de división del trabajo social, según Durkheim. Esta división y especialización de labores conlleva a la formación de estereotipos diferenciados del comportamiento femenino y masculino, que incluye la asignación de rasgos psicológicos para cada sexo y desarrollo de características adecuadas. Paulatinamente, la cultura y sus valores que la sustentan refuerzan esta diferenciación y jerarquización de las posiciones sociales de hombres y de mujeres. Luego, la religión, la filosofía y la literatura hacen su trabajo de contribuir a ideologizar aquello que la historia construyó, para que se aprenda y asimile como conducta normal. Por último, el derecho normativiza las costumbres. Como se ve, el derecho va detrás de la realidad, pues tiende a consolidar mediante la norma jurídica lo que la realidad ya estableció.

Las relaciones de dominación, sus privilegios e injusticias, se mantienen y reiteran en el tiempo, civilización tras civilización, debido a la violencia que se ejerce sobre los sujetos oprimidos, haciendo aparecer como permisibles unas condiciones de relación insufribles. Para Bourdieu, P. (2000) la supremacía masculina y la forma en la que se aplica y soporta es el mejor ejemplo de una sumisión que cuesta 
¿es eficaz la respuesta penal?

Criminological approach of gender and intrafamily violence

is the criminal response effective?

entender, si no fuera consecuencia de lo que llama la violencia simbólica, que se ejerce esencialmente a través de los caminos de la comunicación, conocimiento, reconocimiento o sentimiento.

Hay una admisión y tolerancia ideológica entre dominadores y dominados, debido a las creencias y sentimientos en la producción y la reproducción de la hegemonía masculina como aspecto medular del orden establecido. La diferencia natural entre hombres y mujeres se entiende equivocadamente como desigualdad y jerarquía, que se extiende social y culturalmente, constituyendo el sistema social del patriarcado. Es decir, de los elementos biológico y social surge la creencia cultural. Esa equivocación surge, en un primer momento, en la familia y se extiende a la sociedad.

Los patrones culturales hacen prisioneros del carácter dominante también al varón, quien aprende históricamente en el proceso de socialización su rol social. Así, se ve constreñido a certificar su predominio, su fuerza, porque para él eso resulta ser sinónimo de virilidad, a la que asocia con la capacidad sexual, aptitud para el enfrentamiento y ejercicio de la violencia. Y lo es porque históricamente al varón le tocó el papel de enfrentarse a la naturaleza y a otros varones. Si no lo hace lo asalta la idea de que no es varón, de ahí que tienda a demostrarlo, reafirmándose en su creencia, generando conflictos, enfrentándose $\mathrm{y}$, finalmente, violentando a la mujer. Cuanto más miedo de no saberse varón exista, más se exhibirán los rasgos que quieren reflejarla. Aquí detonan simultáneamente la exaltación narcisista del ego y las pulsiones sociales.

Los aspectos ideológicos, las creencias y los sentimientos, importan mucho en materia de violencia, más aún en hacer que ésta tenga aceptación social y en su reproducción, pues tiene el efecto de aplicar a las relaciones de dominación las categorías construidas por los dominadores, como si fueran categorías normales. El orden social, con sus ideas, hábitos y costumbres, se impone y hace que las personas adecuen su comportamiento para responder al orden social. No es entonces que el varón esté enfermo, trastornado o sea un ser monstruoso, sino que ha nacido, ha sido formado, educado y socializado en un orden social de violencia contra la mujer, por lo que, al primer conflicto, por leve que sea, reacciona violentamente.
Es la sociedad la que prepara el campo ideológico y hace el trabajo previo que asegura el dominio del varón y la adquisición de los usos correspondientes, que permiten la aceptación, expresa o tácita, de las creencias patriarcales predominantes en la sociedad.

Es un problema complejo el de la violencia de género porque sus causas están enraizadas en la misma formación de la sociedad. De hecho, no solo es un problema individual. Es fundamentalmente un problema social. En ese sentido, no es verdad que sólo por saber el origen socio cultural de la violencia de género sea factible extinguirla. Es un paso importante sin duda, pero debe tenerse presente que puede empeorar la resistencia de los dominadores al sentirse amenazados por el cambio ideológico en las relaciones con las mujeres, no siendo capaces de comprender la necesidad de que la igualdad presida dichas relaciones. El varón es un prisionero del sistema de ideas de la dominación masculina, como producto del proceso de socialización y educación en el que se desarrolla. El efecto es que el varón se ve constreñido a afirmar su superioridad, demostrar su fuerza, a dirigir y gobernar, porque según la creencia dominante eso es virilidad.

Como se puede apreciar, mayor influencia tiene la cultura que la naturaleza humana en la producción de violencia de género. El varón siente miedo de no ser capaz de demostrar suficientemente su virilidad, por lo que se genera agresividad contra la mujer. La violencia contra la mujer pone de manifiesto el vínculo que tiene dicha conducta con la masculinidad en el varón. Por ello, a mayor temor de perderla o duda en poseerla, más excesivamente se exhibirán los atributos que necesitan proyectarla. Por cierto, que es una exhibición grosera e irracional, pero es que la violencia constituye el instrumento más expeditivo a la mano para dominar una situación e imponer la propia voluntad.

\section{Caracteristicas de la violencia de género}

El género identifica las diferencias sociales y culturales entre los varones y las mujeres, a diferencia del sexo, que denota las diferencias biológicas respectivas. Por eso, el género es un constructo cultural que hace la sociedad en su evolución, que no tiene nada que ver con la naturaleza humana. Hasta hace dos 
décadas, por ejemplo, era impensable ver una mujer boxeadora o luchadora o piloteando un avión caza de combate, entre otras actividades deportivas o profesionales de alto riesgo, que son comunes actualmente. Ergo, no es posible seguir considerando dichas actividades como masculinas. Viceversa, hasta hace poco era impensable que un varón tenga como medio de vida el diseño de ropa, la cosmética, la cocina, entre otras actividades consideradas netamente femeninas, que hoy tienen gran arraigo entre los varones.

La violencia del varón contra la mujer se llama violencia de género porque está indisolublemente ligada a su explicación, en tanto y en cuanto la sufren las mujeres por el simple hecho de ser mujeres, es decir, es desplegada por los hombres para mantener el control y el dominio sobre las mujeres, a diferencia de otro tipo de violencia que no tienen relación con ser varón o mujer.

La sociedad ha construido una cultura con base en un código patriarcal que representa la supremacía de la masculinidad sobre la mujer, conocida como machismo, ideología que postula considerar a la mujer como un ser inferior al varón, por lo que a la luz de esta creencia sería normal maltratarla. La violencia masculina hace sentir inferior a la mujer y, al mismo tiempo, refuerza la idea de usar la violencia contra ellas. Este círculo vicioso tiene un colosal poder de coacción. Para dar una idea de lo que significa esta construcción cultural machista, baste con decir que la mujer está sujeta a normas de comportamiento rígidas, de acatamiento, obediencia y circunspección sexual, cuyo incumplimiento se pretende para justificar la violencia de la que es objeto.

Castells, M. (1998) define el patriarcado como:

Una estructura básica de todas las sociedades contemporáneas. Se caracteriza por la autoridad de los hombres sobre las mujeres y sus hijos, impuesta desde las instituciones. Para que se ejerza esa autoridad, el patriarcado debe dominar toda la organización de la sociedad, de la producción y el consumo a la política, el derecho y la cultura. Las relaciones interpersonales están también marcadas por la dominación y la violencia que se originan en la cultura y en las instituciones del patriarcado (Página 159).
Si bien es verdad que este código patriarcal está siendo impactado por la ideología denominada de la liberación femenina, aun se resiste a extinguirse y la evidencia es que la violencia se incrementa.

La violencia de género es, asimismo, instrumental por cuanto es un medio para perpetuar la dominación y el control sobre la mujer. No es un fin en sí mismo. En efecto, al usar la violencia de género, el varón pretende conservar el vínculo con la mujer obligándola a hacer o dejar de hacer algo contar su voluntad. Quiere someterla, no romper con ella.

Como se puede observar, la violencia de género está insertada en el sistema social, de ahí que sea estructural y no episódica. También la caracteriza el hecho de ser transversal a todas las clases sociales y las diferentes etapas de la vida. Aún en la actualidad, la posición que ocupa la mujer en el seno familiar, disminuye su posición social.

La violencia de género se compendia en ataques individuales, sin embargo están configurados como un componente social de dominio del grupo masculino sobre el femenino. Es este el sentido en el que se entiende que el conjunto de la sociedad se haya resistido hasta la actualidad a dar una respuesta eficaz a este tipo de violencia.

Otra característica de la violencia de género tiene que ver con el ligamen existente con las dependencias sociales, económicas y psicológicas, entre agresor y víctima Es viviendo la insufrible experiencia de la violencia que la mujer se prepara para aceptar el dominio masculino y creer que su existencia se justifica solamente en depender de cualquier forma de un varón. Así, un matrimonio estable y una familia unida están asociados con el éxito personal de la mujer. Por eso soporta la violencia.

La violencia de género también se caracteriza porque no es natural sino aprendida a través de un proceso de educación y socialización, que se legitima mediante ciertos valores ancestrales como el sexismo, que consiste en el desprecio a la mujer y la creencia de que hay que dominarla y someterla; y la misoginia que es el odio a las mujeres, vinculada a su supuesta inferioridad. La socialización crea las identidades y el hombre -varón y mujer- se nutre de ellas durante su vida. 
¿'s eficaz la respuesta penal?

Criminological approach of gender and intrafamily violence

is the criminal response effective?

\section{LA VIOLENCIA INTRAFAMILIAR}

En el término intrafamiliar se comprenden múltiples fenómenos de violencia que se dan entre los miembros de una familia, como la de los padres contra los hijos, de éstos contra aquellos, entre cónyuges, convivientes y demás miembros de una familia.

El núcleo familiar es un espacio neurálgico para el aprendizaje en general y el aprendizaje de la violencia en particular. De lo expuesto precedentemente, se deduce que existe -pervive- socialmente un patrón de conducta y de resolución de conflictos que es desigual. Paradigmáticamente, se comparte un hogar y las experiencias de convivencia sin destacar el conflicto de género ni hacerlo evidente, por el contrario, se busca por todos los medios de mantenerlo soterrado para no sentir el fracaso ni el dolor subsecuente. En esa línea, el orden y la armonía se asumen con un valor superior a la negociación y composición del conflicto, porque hay detrás una estructura de poder patriarcal, la misma que eleva a la categoría de ideal de la armonía familiar el sometimiento a la autoridad del varón padre de familia y desconoce la realidad humana que empuja cotidianamente a la violencia.

Bajo la ideología de la armonía, subyacen ideas desvalorizadoras de las mujeres que están vinculadas a la división del trabajo en el hogar. Con estas ideas se refuerza la desigualdad entre los cónyuges o convivientes. La dependencia económica es un factor coadyuvante de la violencia porque vigoriza estructuralmente la debilidad de la mujer.

Este tipo de violencia al interior de la familia es un fenómeno común y extendido, no es algo enfermizo, raro o esporádico, sino usual y acostumbrado que se da en distintos grados de manera transversal en todas las capas de la población, para mantener la idea de la supremacía masculina, es decir, las relaciones desiguales. Evidentemente, esta violencia se extinguirá si la relación se equipara y se hace a un lado la creencia en la inferioridad de la mujer por parte de hombres y de mujeres.

La violencia en la familia actúa como un dispositivo de control y castigo, para limitar, debilitar y anular la personalidad y el desarrollo de los miembros de la familia contra los que se dirige, cuando no se someten suficientemente, desdeñando su calidad de personas con dignidad, inteligencia y voluntad.

Importa desde el punto de vista criminológico distinguir entre causas y factores. En el caso de la violencia familiar y de género, la causa es, sin duda alguna, de índole antropológica, cultural y social, en cambio los factores aparecen unidos al alcoholismo, drogadicción, síndrome de Otelo, trastornos de personalidad, pobreza, entre otros, lo que da la sensación de que éstas fueran las causas, pero no es así. El sentido de pertenencia de la mujer y miembros de la familia a cargo del varón, trasmitido de generación en generación, configura a la violencia familiar y de género como un problema social estructural, de lo contrario el problema sería uno de salud pública, como algunos líderes de opinión han manifestado recientemente con ocasión de los últimos clamorosos casos de feminicidio ocurrido en nuestro país.

En este sentido, la prevención de la violencia de género e intrafamiliar debe lograrse mediante la resocialización desde el seno familiar y hasta la vida social, en la que los medios de comunicación social tienen un deber que cumplir en la colaboración que deben al estado en la educación y la formación moral y cultural de la población, establecido por el artículo 14 in fine de la Constitución Política del Estado. Es muy importante educar a los jóvenes de otra forma. Sin embargo, observamos cómo los medios de comunicación aún continúan proyectando la imagen sexualizada e instrumental de la mujer. Definitivamente, no es democrático, como debe corresponder a nuestra forma de estado, que no exista igualdad, como lo establece la Constitución Política.

\section{LA REACCION PENAL}

Ante una sociedad con un código cultural patriarcal, que avala relaciones anómicas y asimétricas entre varón y mujer y miembros de una familia a cargo del varón, el estado reacciona ejercitando el derecho a castigar, que se conoce como ius puniendi, lo cual ya implica una crítica, acerca de qué legitimidad puede tener un castigo si el infractor ha sido formado y socializado para adecuar su comportamiento precisamente en el sentido de desarrollar conductas infractoras debido a la vigencia de patrones culturales ancestrales. Es 
de suponer que toda persona sujeta a un orden normativo debe ser previamente enseñada a seguir estándares de conducta adecuados a dicho orden, para poder castigar cuando su comportamiento se aparta de dichas normas.

Ahora bien, el ejercicio del ius puniendi estatal se realiza de manera rigurosa y severa, imponiéndose penas gravísimas, lo que supone una intervención negativa en el infractor, que resulta etiquetado y estigmatizado a perpetuidad por la sociedad y el estado, porque esas son las características perversas del sistema penal nacional, sin que pueda aspirar a una resocialización como finalidad de la pena, ya que reiteramos no se trata de una conducta volitiva $\mathrm{e}$ independientemente individual sino de la exteriorización de un problema estructuralmente social. Esto se encuentra demostrado con la reiteración y la reincidencia, así como la repetición de casos de violencia de género cada vez que se anuncian y/o aplican penas sumamente duras.
Si analizamos el cuadro $\mathrm{N}^{\circ} 1^{3}$, que sigue a continuación, se establece que de los cinco primeros meses de los años 2017 y 2018 , en cuatro de ellos existen incrementos de los casos de violencia familiar, con variaciones que van del $22 \%$ al $100 \%$ y en el único mes en el que no hay incremento la cantidad de casos se mantiene igual, lo cual pone de manifiesto la escalada del problema social.

\begin{tabular}{|c|c|c|c|}
\hline Mes / año & 2018 & 2017 & Var. $\%$ \\
\hline Enero & 10 & 8 & $25 \%$ \\
\hline Febrero & 12 & 12 & $0 \%$ \\
\hline Marzo & 11 & 9 & $22 \%$ \\
\hline Abril & 10 & 5 & $100 \%$ \\
\hline Mayo & 19 & 10 & $90 \%$ \\
\hline Total & 62 & 44 & $41 \%$ \\
\hline
\end{tabular}

Al evaluar el cuadro $\mathrm{N}^{\circ} 3^{4}$, que sigue a continuación y que muestra los casos con características de feminicidio, que es la

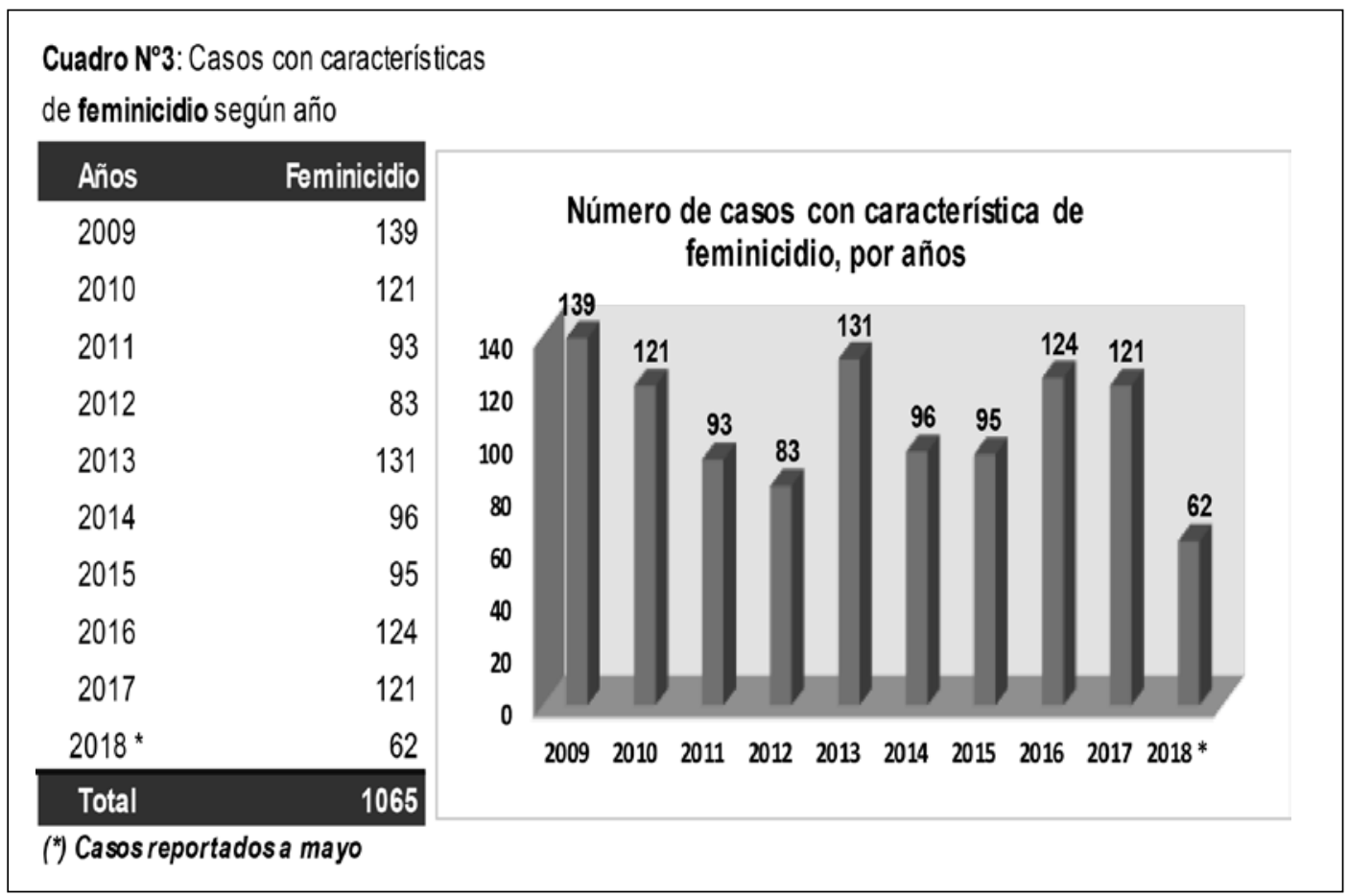

3 Fuente: Ministerio de la Mujer y Poblaciones Vulnerables (2018). Reporte Estadístico de Casos con características de feminicidio atendidos en los centros de emergencia mujer. Periodo: Enero - Mayo - 2018. Recuperado del sitio de internet: https://www. mimp.gob.pe/files/programas_nacionales/pncvfs/estadistica/boletin_mayo_2018/paginas/A1.xlsx

4 Fuente: Ministerio de la Mujer y Poblaciones Vulnerables (2018). Reporte Estadístico de Casos con características de feminicidio atendidos en los centros de emergencia mujer. Periodo: Enero - Mayo - 2018. Recuperado del sitio de internet: https://www. mimp.gob.pe/files/programas_nacionales/pncvfs/estadistica/boletin_mayo_2018/paginas/A1.xlsx 
¿es eficaz la respuesta penal?

Criminological approach of gender and intrafamily violence

is the criminal response effective?

modalidad más grave de violencia contra a mujer, durante el período 2009 al mes de mayo de 2018, se observa que se incrementa cada dos años, pero en los demás años permanece en niveles altos, lo cual evidencia que se trata de un problema social que la sanción penal no puede enervar o solucionar.
Al examinar el cuadro que sigue ${ }^{5}$, que muestra la cantidad de denuncias en el período 2011 al 2017, se advierte que la cantidad de denuncias por violencia familiar es de 187, 270, mayor que las denuncias contra la vida, el cuerpo y la salud; contra la seguridad pública; contra la libertad; contra la familia; y que el rubro

\begin{tabular}{|c|c|c|c|c|c|c|c|}
\hline Indicador & 2011 & 2012 & 2013 & 2014 & 2015 & 2016 & 2017 \\
\hline Denuncias por comisión de delitos & 240438 & 271813 & 299474 & 326578 & 349323 & 355876 & 399869 \\
\hline Contra el patimonio & 168618 & 185357 & 204935 & 224753 & 242697 & 242653 & 265219 \\
\hline Contra la vida, el cuerpo y la salud & 28486 & 39744 & 33613 & 36643 & 37057 & 44342 & 50597 \\
\hline Contra la seguridad pública & 15932 & 14839 & 28175 & 30388 & 40150 & 38150 & 49385 \\
\hline Contra la libertad & 15812 & 17848 & 18459 & 19379 & 18730 & 20428 & 22660 \\
\hline Contra la familia & 3329 & 3684 & 4755 & 3354 & 2013 & 2318 & 2695 \\
\hline Otros delitos $1 /$ & 8261 & 10341 & 9537 & 12061 & 8676 & 7985 & 9313 \\
\hline Denuncias por violencia familiar & 110844 & 124057 & 122901 & 135874 & 137742 & 164488 & 187270 \\
\hline Fisica & 57819 & 64948 & 61651 & 65380 & 67006 & 73413 & 76011 \\
\hline Psicologica & 38366 & 39030 & 37958 & 42829 & 42468 & 54927 & 69969 \\
\hline Otro tipo 2l & 14659 & 20079 & 23292 & 27665 & 28268 & 36148 & 41290 \\
\hline Mujeres victimas de violencia familiar & 100611 & 110845 & 110297 & 121218 & 122197 & 146261 & 165164 \\
\hline Hombres victimas de violencia familiar & 10233 & 13212 & 12604 & 14656 & 15545 & 18227 & 22106 \\
\hline Denuncias por violencia sexual & 5321 & 6172 & 5807 & 5614 & 5702 & 5683 & 7113 \\
\hline Mujeres victimas & 5049 & 5795 & 5438 & 5201 & 5311 & 5288 & 6621 \\
\hline Hombres victimas & 272 & 377 & 369 & 413 & 391 & 395 & 492 \\
\hline Denuncias de vehiculos robados & 15881 & 16357 & 18927 & 17988 & 16501 & 17544 & 18106 \\
\hline Vehiculos recuperados & 11736 & 11597 & 11202 & 11955 & 12629 & 12991 & 12676 \\
\hline Número de accidentes de tránsito & 110341 & 121621 & 118809 & 123786 & 95532 & 89304 & 88168 \\
\hline Denuncias de personas desaparecidas & 3157 & 3341 & 3529 & 4499 & 4152 & 4343 & 4692 \\
\hline
\end{tabular}

genérico otros, apenas superada por la cantidad de denuncias por delitos contra el patrimonio, lo que ubica a la violencia familiar en el segundo lugar en la comisión de delitos denunciados (criminalidad aparente), lo cual subraya la magnitud del problema socio cultural en que estamos inmersos como sociedad.
Evidentemente, las cifras mostradas corresponden a los casos que llegan a conocimiento de las entidades públicas por existir denuncia de por medio, lo que quiere decir que detrás hay una criminalidad real que es mucho mayor si se considera que numerosas mujeres no denuncian la violencia por las

5 Fuente: INEI (2018). Estadisticas de Seguridad Ciudadana. Informe Técnico $\mathrm{N}^{\circ} 3$. Recuperado del sitio de internet: https://www. inei.gob.pe/media/MenuRecursivo/boletines/03-informe-tecnico-n03_estadisticas-seguridad-ciudadana_nov17_ab18.pdf 
consideraciones socio culturales que hemos desarrollado.

En materia normativa penal, la Ley $\mathrm{N}^{\circ} 30068$ de julio de 2013 -Ley que incorpora el Articulo 108-B al Código Penal y modifica los Artículos 107, 46-B y 46-C del Código Penal y el Artículo 46 del Código de Ejecución Penal, con la finalidad de prevenir, sancionar y erradicar el feminicidio- establece una pena privativa de libertad no menor de 15 años al que mata a una mujer por su condición de tal, en determinados contextos. Posteriormente, la Ley $\mathrm{N}^{\circ} 30819$ de julio de 2018 -Ley que modifica el Código Penal y el Código de los Niños y Adolescentesagrava la pena por el feminicidio a no menor de 20 años de pena privativa de la libertad y no menor de 30 años si concurren circunstancias agravantes. En el lapso de 5 años transcurridos entre la promulgación de ambas normas, el feminicidio no se redujo como aparece de los cuadros estadísticos antes indicados.

A su vez, la Ley $\mathrm{N}^{\circ} 29282$ de noviembre de 2008 -Ley que modifica el Texto Único Ordenado de la Ley de Protección Frente a la Violencia Familiar, Ley N ${ }^{\circ} 26260$, y el Código Penal- incorpora el tipo penal de lesiones graves por violencia familiar, estableciendo una pena privativa de la libertad entre cinco y diez años y suspensión de la patria potestad, y si la víctima muere a consecuencia de la lesión y el agente pudo prever este resultado, la pena será no menor de seis ni mayor de quince años; ni la Ley $\mathrm{N}^{\circ} 30364$ de noviembre de 2015 -Ley para prevenir, sancionar y erradicar la violencia contra las mujeres y los integrantes del grupo familiar- han servido para frenar la violencia familiar y de género.

Asimismo, el Decreto Legislativo $N^{\circ} 1323$ de enero de 2017 -Decreto Legislativo que fortalece la lucha contra el feminicidio, la violencia familiar y la violencia de géneropena las lesiones graves por violencia contra las mujeres e integrantes del grupo familiar, cuando la víctima muere a consecuencia de la lesión y el agente pudo prever ese resultado, con una pena no menor de quince ni mayor de veinte años, sin embargo, tampoco ha servido para reducir la violencia de género y familiar.

Como se puede apreciar, la solución no pasa por modificar las normas penales para crear tipos penales nuevos ni agravar las penas o incrementar la cantidad de agravantes, si se deja subsistente la causa, la cual en este caso no es intervenida en nada por la legislación penal sencillamente porque no es su objeto, entonces lo que se hace es populismo punitivo, porque se utiliza electoralmente el derecho penal por parte de los políticos para obtener réditos o se usa el derecho penal guiado por la idea -equivocada- de que mayores penas menos delito; que las penas ayudan a reforzar el consenso moral existente en la sociedad.

Se observa que la función del derecho penal ya no es solamente castigar sino se pretende que también genere una sensación de seguridad y educación (i?), como era en los tiempos medievales en los que se confundía el derecho y la moral, de ahí que veamos un derecho penal autoritario porque la coerción que le caracteriza es ajena a una función pedagógica que no corresponde al thelos penal, razón por la cual hoy en día en nuestra sociedad se aprecia el castigo como un elemento importante del orden democrático, aplazando la prevención.

Este populismo punitivo se inscribe en una política neopunitivista, caracterizada por el dogma de que el ius puniendi debe alcanzar toda la vida social, en un movimiento expansivo (panpenalismo) que militariza a la sociedad al ejercer un cerrado control social vertical.

Lo que debería hacerse para prevenir la violencia de género e intra familiar es, cambiar el patrón cultural patriarcal y machista existente, concienciar a la población en el principio de dignidad humana e igualdad de todos, así como en la internalización de la sana costumbre democrática de la comunicación y la deliberación, el respeto y la tolerancia, la cooperación y la colaboración. Como todo lo duradero, implica un trabajo educativo y de re socialización sostenido de largo plazo. Mientras tanto habrá que seguir castigando con la cárcel solo las conductas de grave violencia. Para las de menor violencia se puede aplicar otras penas previstas en la ley penal. Pero hay que comenzar de una vez para ver los frutos posteriormente. La cárcel no solucionará el problema. La experiencia que estamos viviendo lo demuestra.

Los medios de comunicación social tienen que cumplir un rol fundamental en torno a este problema. Deben ser consecuentes con la dignidad y la igualdad. No ser sensacionalistas. No mostrar noticias ni exhibir a la mujer como 
¿es eficaz la respuesta penal?

Criminological approach of gender and intrafamily violence

is the criminal response effective?

un objeto para excitar el morbo de la gente. Los programas de reality y la publicidad deben también mostrar coherencia con estos postulados igualitarios y evitar el concepto utilitario de mujer. Si de veras se desea terminar con el patrón cultural que produce la violencia de género, debemos ser conscientes de que la cruzada a iniciar requiere el concurso de todos. Lo demás es populismo farsante.

\section{CONCLUSIONES}

La violencia en general es el recurso a la fuerza para resolver un conflicto intersubjetivo de intereses imponiendo la voluntad de uno de ellos sobre el otro, en su perjuicio, por lo que el estado la criminaliza para sancionarla. La violencia de género es una manifestación estructural de poder del varón sobre la mujer, que responde a un patrón socio cultural patriarcal, con la finalidad de mantener la subordinación de ésta y la dominación de aquel. Igualmente, la violencia intrafamiliar es el ejercicio de poder arbitrario en el seno doméstico que se encuentra a cargo del varón. Como estas conductas violentas afectan la dignidad humana y el derecho a la igualdad, libertad, vida, salud e integridad personal, el estado también las criminaliza y sanciona.

La causa de la violencia de género y de la violencia intrafamiliar radica en el paradigma cultural de la supremacía del varón, nacido de una estructura de control y dominación patriarcal transmitida generacionalmente a través de la historia de la humanidad. Los factores de estos tipos de violencia pueden ser de variada índole, tales como la drogadicción, el alcoholismo, el síndrome de Otelo, el mal carácter, la pobreza, entre otros. Los factores no originan la violencia solo constituyen el detonante de algo que subyace en una creencia social generalizada y que es la causa final, cual es el machismo imperante en la sociedad, que no es una actitud individual sino una cosmovisión general y extendida en los miembros de una comunidad.

El hombre no reacciona frente al elemento inductivo, sino ante la interpretación que hace de él, por ello es que para poder comprender -y para juzgar y castigar hay que comprenderuna conducta violenta, no es suficiente conocer la circunstancia en medio de la que la violencia se exterioriza (que es el factor), sino se requiere saber cuál es la interpretación que el sujeto hace de esa situación (que obedece a la causa, que indica la supremacía del varón). En otras palabras, toda persona erige siempre su realidad y la transforma, asignándole significados en función de los cuales estructuran su conducta.

Felizmente, las interpretaciones no son inalterables, por lo que el cambio es factible mediante el conocimiento de la vasta trama de significados del sujeto que atribuye a su realidad desde su particular modo de conocer la realidad. $\mathrm{Y}$ en materia de relación inter género, el varón solo cree que él debe presidir dicha relación, porque así ha sido educado y socializado, porque en ese patrón ha sido formado.

Como el sistema penal subsume la conducta en el tipo penal, demuestra la responsabilidad de quien la ha cometido y lo sanciona, sin abordar las causas sino tan solo el móvil o circunstancia que dio lugar a dicha acción violenta, evidentemente no va a hacer frente a la raíz del problema y, por ende, la solución no va a llegar por la vía penal. Las estadísticas dan cuenta de ello y, lo que es peor, evidencian la reproducción y el incremento de la conducta castigada, debido a la intolerancia respecto a la idea de que así se combate el patrón cultural machista, por lo que se produce inmediatamente la pulsión destinada a reiterar el comportamiento cada vez más gravemente para perseverar en el predominio.

Contrariamente, la criminología como ciencia que estudia el crimen, el criminal, la víctima y el control social, para determinar las causas del crimen con fines político criminológicos, esto es, con el propósito de diseñar una respuesta estatal eficaz e idónea, al establecer las causas criminógenas, puede pretender válidamente controlarlas e intervenir positivamente en los varones y mujeres para modificar sus ideas, paradigmas, creencias, usos, costumbres y hábitos, de manera tal de prevenir el uso de la violencia en las relaciones de género $\mathrm{y}$ familiares.

De otra manera, no se gana nada encarcelando a los violentadores en materia de género y familia, no se compone ni resuelve el conflicto, por el contrario, se mantiene vigente pues está demostrado por la experiencia que, a penas más graves, la reacción es de más conductas violentas. Por ello la respuesta penal no es eficaz para prevenir y reducir la violencia de género e intrafamiliar. Creemos que la agrava. 


\section{FUENTOS DE INFORMACIÓN}

\section{Fuentes bibliográficas}

Alberdi, Inés y Matas, Natalia (2002) La violencia doméstica. Colección Estudios Sociales $\mathrm{N}^{\circ} 10$. Fundación La Caixa, Barcelona.

Bourdieu, P. (2000). La dominación masculina. Anagrama, Barcelona.

Castells, M. (1998). La era de la información: Economía, Sociedad y Cultura, Vol.2 El poder de la Identidad. Editorial Alianza, Madrid.
Lerner, G. (1990). La creación del patriarcado. Editorial Crítica, Barcelona.

\section{Fuentes electrónicas}

Garza Treviño, E. (1994) Neurobiological factors in aggressive behavior. Hosp Commun Psychiatry. Disponible en: https://www. researchgate.net/publication/15272529 Neurobiological_Factors_in_Aggressive_ Behavior 